\title{
Recurrent hypoglycaemia in a type 2 diabetes patient - diagnostic difficulties
}

Joanna Grycewicz ${ }^{1,2}$, Zdzisława Ścibór ${ }^{1,2}$, Jarosław B. Ćwikła ${ }^{3}$, Andrzej Lewiński²,4, Katarzyna Cypryk¹,2

\begin{abstract}
1Department of Diabetology and Metabolic Diseases, Medical University of Lodz, Poland ${ }^{2}$ Department of Endocrinology and Metabolic Diseases, Polish Mother's Memorial Hospital - Research Institute (RI PMMH), Lodz, Poland

${ }^{3}$ Department of Radiology and Diagnostic Imaging, Postgraduate Medical Centre and Central Clinical Hospital of the Ministry of Internal Affairs and Administration, Warsaw, Poland

${ }^{4}$ Department of Endocrinology and Metabolic Diseases, Medical University of Lodz, Poland
\end{abstract}

Submitted: 2 November 2008

Accepted: 19 April 2009

Arch Med Sci 2010; 6, 1: 126-129

DOI 10.5114/aoms.2010.13520

Copyright (c) 2010 Termedia \& Banach

\begin{abstract}
Hypoglycaemia is the most frequent acute complication of diabetes, regardless of the type of diabetes and the treatment method. Hormonally active tumours of the pancreas, insulinomas, which belong to digestive tract neuroendocrine tumours, constitute one of the less frequent causes of hypoglycaemia. This paper presents a case of a 60-year-old type 2 diabetes patient with recurrent hypoglycaemic events, in whom an insulin-secreting hepatic neuroendocrine tumour was diagnosed. We suggest performing a diagnostic workup taking into consideration insulinoma in patients with diabetes who experience frequent otherwise inexplicable hypoglycaemic events, particularly when they recur despite decreased dose or discontinuation of hypoglycaemic agents.
\end{abstract}

Key words: hypoglycaemia, insulinoma, neuroendocrine tumour, type 2 diabetes.

\section{Introduction}

Hypoglycaemia is the most frequent acute complication of diabetes regardless of the type of diabetes and the kind of therapy applied. Miller et al. observed hypoglycaemia in $12 \%$ of patients treated by diet alone, in $16 \%$ of those treated with oral hypoglycaemic agents, and in as many as $30 \%$ of those using insulin [1]. The most frequent causes of hypoglycaemia in patients with type 2 diabetes treated with oral hypoglycaemic agents are: dose not adjusted for meals and physical activity, renal and/or hepatic dysfunction, administration of certain drugs ( $\beta$-blockers, ACE inhibitors, sulphonamides) and alcohol consumption. Hormonally active tumour of the pancreas, insulinoma, which belongs to digestive tract neuroendocrine tumours (NET), is a very rare cause of hypoglycaemia. Such tumours, which derive from pancreatic $\beta$ cells of Langerhans and secrete insulin, are insignificantly more frequent in women, with the reported incidence of 4 cases per million subjects per year [2]. Insulinomas are usually benign, occur as single tumours and are almost always located in the pancreas. In a small percentage these tumours may be multifocal (about 10\%, particularly in the course of MEN1) or malignant (8-10\%), resulting in local infiltration and metastases to the liver and periaortic nodes [3]. The clinical
Corresponding author: Joanna Grycewicz, MD, PhD Department of Diabetology and Metabolic Diseases Medical University of Lodz Rzgowska St. 281/289 93-338 Lodz, Poland Phone: +48 422711153 Phone/fax: +48 422711499 E-mail: jgrycewicz@mp.pl 
picture is characterized by symptomatic hypoglycaemia associated with inappropriately increased plasma insulin level [4]. In our study we present a case of a 60-year-old patient with type 2 diabetes, who was diagnosed with an insulin-secreting hepatic neuroendocrine tumour of aggressive clinical course, manifesting with clinical features of insulinoma: recurrent hypoglycaemic events impossible to be explained by treatment errors.

\section{Case report}

A 60-year-old overweight female $\left(\mathrm{BMI}=27 \mathrm{~kg} / \mathrm{m}^{2}\right)$ with type 2 diabetes was admitted to our department in August 2007 due to recurrent episodes of hypoglycaemic episodes below $40 \mathrm{mg} / \mathrm{dl}$, that had occurred over several months prior to admission. Diabetes was diagnosed in November 2006 based on fasting glucose levels over $125 \mathrm{mg} / \mathrm{dl}$ and postprandial glycaemia over $200 \mathrm{mg} / \mathrm{dl}$ observed more than twice. Her past history included chronic gastritis and duodenitis, cholecystolithiasis, and ventricular arrhythmia treated with amiodarone, which resulted in amiodarone-induced thyrotoxicosis (2003). Diabetes had been managed initially with a diabetic diet alone, but three months prior to hospitalization a small dose of the sulphonylurea (SM) derivative glimepiride was added. As glimepiride was assumed to be a possible cause of hypoglycaemia, it was discontinued and metformin (MF) was administered. Nevertheless, due to poor tolerance of metformin and elevated glucose levels the patient still took SM tablets occasionally.

Physical examination on admission revealed blood pressure of $130 / 85 \mathrm{mmHg}$, pulse rate regular 85 beats/min, heart sounds were normal, the chest was clinically clear and all peripheral pulses were palpable. Fundoscopy showed no evidence of retinopathy.

Following hospital admission oral hypoglycaemic agents were discontinued and insulin was not administered. Glucose levels ranged from 95 to $133 \mathrm{mg} / \mathrm{dl}$ at fasting and before meals with marked postprandial peaks up to $330 \mathrm{mg} / \mathrm{dl}$. Glycosylated haemoglobin $\left(\mathrm{HbA}_{1 \mathrm{c}}\right)$ was $6.3 \%$. Further investigational biochemical laboratory tests revealed elevation of serum alanine aminotransferase (ALT) $112 \mathrm{U} / \mathrm{l}$ (ref. range: 10-36 U/l), aspartate aminotransferase (AST) $99 \mathrm{U} / \mathrm{l}$ (ref. range: 10-30 U/l) and $\gamma$-glutamyl transferase (GGTP) $528 \mathrm{U} / \mathrm{l}$ (ref. range: 5-39 U/I). There was also slight elevation of alkaline phosphatase (ALP) $181 \mathrm{U} / \mathrm{l}$ (ref. range: 42-141 U/l). Bilirubin levels were normal $(0.75 \mathrm{mg} / \mathrm{dl}$, ref. range: $0.2-1.0 \mathrm{mg} / \mathrm{dl}$ ) and serological testing showed no evidence of hepatitis B and C. Moreover, a slightly higher level of serum carcinoembryonic antigen (CEA) $5.46 \mathrm{ng} / \mathrm{ml}$ (ref. range: to $3.4 \mathrm{ng} / \mathrm{ml}$ ) was observed. Renal function parameters and serum electrolytes were within normal limits. Serum thyroid hormones were normal and antithyroid antibodies were not detected. The erythrocyte sedimentation rate during the first hour (ESR) was $8 \mathrm{~mm} / \mathrm{h}$. The 72-h fasting test was performed and failed to demonstrate hypoglycaemic episodes; the serum insulin concentration was below $2.0 \mu \mathrm{U} / \mathrm{ml}$ (ref. range: 6-27 $\mu \mathrm{U} / \mathrm{ml}$ ) at the end of the test.

Abdominal ultrasonography (USG) and computed abdominal tomography (CT) showed an extensive disintegrating hyperechogenic hepatic mass of $100 \times 75 \times 85 \mathrm{~mm}$ in diameter. There was evidence of modelling of the portal vein and bile duct structure. There were also numerous focal lesions up to $28 \mathrm{~mm}$ in the remaining parenchyma, without hepatomegaly or pathological changes in other abdominal organs or retroperitoneal space. Awaiting further diagnostic workup, the patient was asked to control occasional episodes of postprandial hyperglycaemia with small doses of the fast acting insulin analogue lispro administered subcutaneously.

In September 2007 fine needle aspiration biopsy (FNAB) of the liver was performed. Histopathology revealed a neoplasm that consisted of cells of low pleomorphism showing neuroendocrine origin. Then, somatostatin (SST) receptor scintigraphy (SRS) was performed with 99mTc-HYNIC-TOC and SST receptor expression was demonstrated in the liver focal lesions without metastatic spread to other organs.

During the next hospitalization, in October 2007, despite insulin discontinuation, two incidents of hypoglycaemia below $40 \mathrm{mg} / \mathrm{dl}$ were observed; in one case insulin level was $289 \mu \mathrm{U} / \mathrm{ml}$. Moreover, elevated serum levels of chromogranin A (CgA) $506.5 \mathrm{U} / \mathrm{l}$ (ref. range: 2-18 U/l), human chorionic gonadotrophin- $\beta$ subunit (BhCG) $10.66 \mathrm{U} / \mathrm{l}$ (ref. range: $<6.0 \mathrm{U} / \mathrm{l}$ ) and urinary 5-hydroxy indolic acetic acid (5-HIAA) 26.3 mg/24 h (ref. range: 0.7-8.0 mg/ $24 \mathrm{~h}$ ) were detected. The $24 \mathrm{~h}$ secretion patterns of adrenocorticotropin and cortisol and the urinary concentrations of adrenaline, noradrenaline, dopamine, vanillylmandelic acid and serum $\alpha$-fetoprotein were normal. Despite the use of several diagnostic methods (abdominal USG, abdominal and thoracic CT, colonoscopy and gastroscopy) no obvious pancreatic lesion was recognized. In view of the advanced stage of the hepatic tumour, further investigation, such as endoscopic ultrasound (EUS), was abandoned. After surgical consultation the patient was disqualified from surgical treatment owing to the progression of the neoplastic process and the location of the main tumour mass in a non-operable site (liver hilus).

Long-acting SST analogue (Sandostatin LAR $20 \mathrm{mg}$ per month) in 3-month therapy resulted in near normal glucose levels and diminished 
incidence of hypoglycaemia, followed by reduction of CgA level (73.3 U/l). Unfortunately, abdominal CT revealed neoplasm progression: hepatomegaly to $118 \times 97 \times 132 \mathrm{~mm}$ with evidence of necrosis, numerous focal lesions up to $28 \mathrm{~mm}$, with the involvement of para-aortal and mesenteric lymph nodes. As the neoplasm progressed, three cycles of radioisotope therapy with Y-90 DOTA TATE with a total dose of $3.35 \mathrm{GBq}$ were applied and further treatment with long-acting somatostatin analogue (Sandostatin LAR 30 mg per month) was continued. Nevertheless, the patient experienced severe hypoglycaemic incidents. Laboratory evaluation during one of the documented episodes showed low plasma glucose of $29 \mathrm{mg} / \mathrm{dl}$, elevated insulin of $136 \mu \mathrm{U} / \mathrm{ml}$ (ref. range: $2.6-24.9 \mu \mathrm{U} / \mathrm{ml}$ ), and C-peptide of $13.3 \mathrm{ng} / \mathrm{ml}$ (ref. range: $0.7-1.3 \mathrm{ng} / \mathrm{ml}$ ). After starting diazoxide therapy, she manifested no symptoms of hypoglycaemia, but her blood glucose levels increased.

Six months after radioisotope therapy, the patient is being treated with insulin lispro (6-8 units with each meal), NPH insulin 12 units at night, longacting SST analogue (30 mg per month) and diazoxide (50 $\mathrm{mg}$ every other day). She has no symptoms of hypoglycaemia and her blood glucose levels on fasting range from 116 to $158 \mathrm{mg} / \mathrm{dl}$ with postprandial peaks to $186 \mathrm{mg} / \mathrm{dl}$.

\section{Discussion}

Hypoglycaemia is a frequent and usually unavoidable phenomenon in patients with type 2 diabetes, particularly those treated with drugs that increase secretion of endogenous insulin. Although in type 2 diabetes impairment in insulin secretion and/or decrease in tissue sensitivity to its activity (insulin resistance) are observed, excessive physical exercise or dietary errors may still result in transient decrease of glucose levels. Discontinuation of glimepiride (sulphonylurea) at the beginning of the diagnostic process was accompanied by diabetic education covering diet, physical activity and healthoriented behaviour. The patient's stable weight was not characteristic of insulinoma either, weight gain being observed in almost half of patients [4].

When therapy-related hypoglycaemia was excluded, other potential causes such as reactive hypoglycaemia, decreased hormone secretion (hypothyroidism, adrenal hypofunction), renal insufficiency, gastrointestinal tract diseases or drug interactions were taken into consideration.

In such circumstances incidents of sudden decrease of plasma glucose level suggested ectopic insulin secretion. The 72 -h fasting test constitutes the golden standard in the diagnosis of hypoglycaemia. In our patient low blood glucose level with inappropriately high insulin level was observed only during the second fasting test performed after 2 months of observation.
A hepatic NET tumour of low grade of differentiation was diagnosed on the basis of liver biopsy. Its clinical features of insulinoma resulted from excessive insulin secretion, leading to recurrent hypoglycaemic episodes.

Surgical treatment involving both the main tumour, usually located in the pancreas, and metastases is the therapy of choice in insulinoma. In the discussed case, diagnostic imaging using conventional methods, CT and USG, failed to show a pancreatic tumour, which is in accordance with the literature data assessing their sensitivity in insulinoma diagnostics at 27-30\% [5]. Moreover, SRS - a very sensitive method for the demonstration of receptor-positive tumours and their metastases - did not visualize any extra-hepatic manifestation. Primary hepatic neuro-endocrine tumours are extremely rare and there are only a few well documented similar cases [6].

Due to the advanced neoplastic process at the time of diagnosis and the disadvantageous location of the main tumour mass, surgical treatment was excluded.

SST analogues play the main role in the pharmacotherapy of hormonally functioning NET, because they usually enable clinical stabilization and resolution of symptoms related to increased hormone secretion [7]. There was evidence of insulinoma metastases regression during that treatment. Efficacy of SST analogues is diminished in about $30 \%$ of insulinoma cases not presenting SST receptors sst2 and sst5 [8]. Moreover, SST analogues may induce acute hypoglycaemia [9].

In our patient, the therapy with a long-acting SST analogue was preceded by confirmation of the presence of SST receptors and by a clinical test with a short-acting SST analogue. The reduction in frequency of incidence of hypoglycaemia with diminished plasma levels of CgA indirectly confirmed the therapy's efficacy.

In the described case glycaemic control was an important issue in the course of diabetes. Due to the tendency to postprandial hyperglycaemia and coexisting hypoglycaemic episodes, lispro therapy was introduced in a dose adjusted to current glycaemia. The choice of rapid-acting insulin analogue was determined by its beneficial short action time and decrease of hypoglycaemia incidence frequency compared to human insulins. Additionally, diazoxide was introduced at a later stage. According to literature reports this agent by lowering insulin secretion enables good glycaemic control in $59 \%$ and diminishes incidence of hypoglycaemia in $38 \%$ of patients with insulinoma [10].

In conclusion, there are few reports of the coexistence of insulinoma and type 2 diabetes. In American studies diabetes was recognized only in 1 patient among 313 hospitalised due to 
insulinoma, which was significantly less frequent than the occurrence of this tumour in the whole population [11].

However, diagnostic workup taking into consideration insulinoma in patients with diabetes should be considered in cases of recurring and inexplicable hypoglycaemic events, particularly when common causes related to medication and concurrent diseases have been excluded.

\section{References}

1. Miller CD, Phillips LS, Ziemer DC, Gallina DL, Cook CB, El-Kebbi IM. Hypoglycemia in patients with type 2 diabetes mellitus. Arch Intern Med 2001; 161: 1653-9.

2. Service FJ, McMahon MM, O'Brien PC, Ballard DJ. Functioning insulinoma-incidence, recurrence, and longterm survival of patients: a 60-year study. Mayo Clin Proc 1991; 66: 711-9.

3. Mittendorf EA, Liu YC, McHenry CR. Giant insulinoma: case report and review of the literature. J Clin Endocrinol Metab 2005; 90: 575-80.

4. Nikfarjam M, Warshaw AL, Axelrod L, et al. Improved contemporary surgical management of insulinomas: a 25-year experience at the Massachusetts General Hospital. Ann Surg 2008; 247: 165-72.

5. Ramage JK, Davies AH, Ardill J, et al. UKNETwork for Neuroendocrine Tumours. Guidelines for the management of gastroenteropancreatic neuroendocrine (including carcinoid) tumours. Gut 2005; 54 Suppl 4: iv1-16.

6. Furrer J, Hättenschwiler A, Komminoth P, Pfammatter T, Wiesli P. Carcinoid syndrome, acromegaly, and hypoglycemia due to an insulin-secreting neuroendocrine tumor of the liver. J Clin Endocrinol Metab 2001; 86: 2227-30.

7. Usukura M, Yoneda T, Oda N, et al. Medical treatment of benign insulinoma using octreotide LAR: a case report. Endocr J 2007; 54: 95-101.

8. Bertherat J, Tenenbaum F, Perlemoine $\mathrm{K}$, et al. Somatostatin receptors 2 and 5 are the major somatostatin receptors in insulinomas: an in vivo and in vitro study. J Clin Endocrinol Metab 2003; 88: 5353-60.

9. Gama R, Marks V, Wright J, Teale JD. Octreotide exacerbated fasting hypoglycaemia in a patient with a proinsulinoma; the glucostatic importance of pancreatic glucagon. Clin Endocrinol (Oxf) 1995; 43: 117-20.

10. Gill GV, Rauf O, MacFarlane IA. Diazoxide treatment for insulinoma: a national UK survey. Postgrad Med J 1997; 73: 640-1.

11. Kane LA, Grant CS, Nippoldt TB, Service FJ. Insulinoma in a patient with NIDDM. Diabetes Care 1993; 16: 1298-300. 